\title{
PERBANDINGAN PENERAPAN MODEL PEMBELAJARAN LEARNING CYCLE (5E) DAN TWO STAY TWO STRAY
}

\author{
Erva Rosa Prima Gayatri*1, Amrul Bahar ${ }^{2}$, Dewi Handayani ${ }^{3}$ \\ Program Studi Pendidikan Kimia Fakultas Keguruan dan Ilmu Pendidikan Universitas Bengkulu \\ ${ }^{1,2,3}$ Program Studi Pendidikan Kimia Universitas Bengkulu \\ e-mail: ervarosapg03@gmail.com
}

\begin{abstract}
The purpose of this research is to know the difference of students' chemistry learning result between experiment 1 class which applied learning cycle model (5E) with experiment 2 class that apply two stay two stray learning model on acid acid base material in class XI IPA in SMA Plus Negeri 7 Bengkulu City. Research conducted is a research with the type of quasi experiment. Chemical learning result data obtained from pretest value and posttest value where the average value of improvement of cognitive learning result for experiment class 1 is 47,78 . And the average value of cognitive learning improvement for experiment class 2 is 54.875 . With testing the hypothesis using $\mathrm{t}$ test with significant level $(\alpha=0,01)$, then got value for titung equal to 2,60 and for ttable got value equal to 2,380 . The results showed that there were significant differences in learning outcomes between classes that applied learning cycle model (5E) with classes that applied the two stay two stray learning model.
\end{abstract}

Keywords : learning cycle (5E), two stay two stray, learning outcomes

\begin{abstract}
Abstrak
Tujuan dari penelitian ini untuk mengetahui perbedaan hasil belajar kimia siswa antara kelas eksperimen 1 yang menerapkan model pembelajaran learning cycle (5E) dengan kelas eksperimen 2 yang menerapkan model pembelajaran two stay two stray pada materi titrasi asam basa di kelas XI IPA di SMA Plus Negeri 7 Kota Bengkulu. Penelitian yang dilakukan merupakan penelitian dengan jenis quasi eksperimen. Data hasil belajar kimia siswa diperoleh dari nilai pretest dan nilai postest dimana nilai rata-rata peningkatan hasil belajar kognitif untuk kelas eksperimen 1 adalah 47,78. Sedagkan nilai rata-rata peningkatan hasil belajar kognitif untuk kelas eksperimen 2 adalah 54,875. Dengan pengujian hipotesis yang menggunakan uji t dengan taraf signifikan $(\alpha=0,01)$, maka didapatkan nilai untuk $\mathrm{t}_{\text {hitung }}$ sebesar 2,60 dan untuk $\mathrm{t}_{\text {tabel }}$ didapatkan nilai sebesar 2,380. Hasil penelitian menunjukkan bahwa terdapat perbedaan hasil belajar yang signifikan antara kelas yang menerapkan model pembelajaran learning cycle (5E) dengan kelas yang menerapkan model pembelajaran two stay two stray.
\end{abstract}

Kata kunci : hasil belajar, learning cycle (5E), two stay two stray

\section{PENDAHULUAN}

Pendidikan adalah faktor penting dalam usaha mencerdaskan kehidupan bangsa, karena itu, prosesproses yang berlangsung sebaiknya dikembangkan dan diarahkan untuk menghasilkan sumber daya manusia yang berkualitas[1]. Keberhasilan proses belajar mengajar merupakan hal utama yang diharapkan dalam melaksanakan pendidikan di sekolah. Komponen utama dalam kegiatan belajar mengajar adalah siswa yang menjadi subjek belajar, bukan menjadi objek belajar [2]. Pendidikan adalah usaha sadar dan terencana untuk mewujudkan suasana belajar dan proses pembelajaran agar peserta didik secara aktif mengembangkan potensi dirinya [3]. Agar kegiatan proses pembelajaran tersebut berlangsung sebaik-baiknya, maka pendidik perlu mengaplikasikan berbagai model, pendekatan, metode dan cara-cara yang tepat agar materi pembelajaran tersampaikan secara efektif dan efisien kepada peserta didik [4]. Salah satu strategi dalam pembelajaran adalah menerapkan pembelajaran kooperatifyang mampu mendorong siswa untuk menemukan dan memahami konsep yang sulit dan dapat mendiskusikan masalahmasalah tersebut dengan teman sebayanya dalam menyelesaikan soal-soal hitungan dan memahami konsep. Beberapa penelitian sebelumnya menunjukkan bahwa pembelajaran kooperatif dapat meningkatkan aktivitas dan hasil belajar [5]. Salah satu model pembelajaran kooperatif yang sudah pernah diterapkan dan sudah terbukti dapat meningkatkan motivasi dan hasil belajar siswa, yaitu pembelajaran Learning cycle (5E) dan model pembelajaran two stay two stray. Pada pembelajaran Learning cycle (5E) merupakan model pembelajaran yang berpusat pada peserta didik (student centered), yang berupa 5 rangkaian tahap (fase) yang diorganisasi sedemikian rupa, meliputi yaitu engagement, exploration explanation, elaboration, dan evaluation. [6]. Model pembelajaran learning cycle terbukti dapat meningkatkan hasil belajar siswa dan mahasiswa [7]. Selanjutnya untuk model pembelajaran 
two stay two stray (dua tinggal dua tamu), siswa dituntut untuk memiliki tanggung jawab dan aktif dalam setiap kegiatan pembelajaran. Pengembangan model pembelajaran ini bermaksud agar dapat menghasilkan model pembelajaran baru yang efektif dan menyenangkan bagi siswa dalam kegiatan pembelajaran.

\section{METODE PENELITIAN}

Penelitian ini bertujuan untuk mengetahui hasil belajar kimia siswa dengan penerapan model pembelajaran Learning cycle (5E) dan model pembelajaran two stay two stray serta melihat perbandingan hasil belajar dengan menggunakan model pembelajaran Learning cycle (5E) dan model pembelajaran two stay two stray. Penelitian ini merupakan jenis quasi experimental. Populasi penelitian adalah siswa kelas XI IPA SMA Plus Negeri 7 Kota Bengkulu dan sampel dipilih 2 kelas yaitu XI IPA 2 dan XI IPA 3. Pada penelitian ini variabel bebas yang digunakan adalah penerapan model pembelajaran Learning cycle 5E kelas eksperimen1 (XI IPA 2) dan model pembelajaran two stay two stray pada kelas eksperimen 2 (XI IPA 3), dengan variabel terikat yaitu hasil belajar siswa pada kelas eksperimen 1 dan kelas eksperimen 2.

Teknik pengumpulan data yang digunakan adalah wawancara, tes, dan dokumentasi. Instrumen penelitian yang digunakan berupa tes yang terdiri dari pretest dan postest, dalam bentuk uraian dengan setiap tes diberikan soal 3 sampai 4 butir soal. Teknik analisa data hasil penelitian menggunakan uji homogenitas, uji normalitas dan uji hipotesis.

Langkah-langkah pembelajaran model Learning Cycle yaitu: fase engagement guru berusaha membangkitkan dan mengembangkan minat dan keingintahuan (curiosity) siswa tentang topik yang akan diajarkan; fase exploration guru membentuk kelompokkelompok kecil antara 3-4 siswa dan memberi kesempatan untuk bekerja sama. Pada tahap ini guru berperan sebagai fasilitator dan motivator; fase explaination guru dituntut mendorong siswa berdiskusi dengan kelompok untuk menjelaskan suatu konsep dengan kalimat atau pemikiran sendiri. Guru berperan sebagai pembimbing dan pengarah dalam diskusi kelas untuk mengambil kesimpulan; fase elaboration siswa menerapkan konsep dan keterampilan yang telah dipelajari dalam situasi baru atau konteks yang berbeda dan fase evaluation siswa dapat melakukan evaluasi diri dengan mengajukan petanyaan terbuka dan mencari jawaban dengan menggunakan observasi, bukti dan penjelasan yang diperoleh sebelumnya [8].

Sedangkan langkah yang dapat ditempuh secara umum dalam model two stay two stray ialah : siswa yang telah dibentuk kelompok oleh guru, duduk dalam kelompoknya masing masing; guru menjelaskan tentang materi pelajaran terlebih dahulu; siswa dibagikan lembar kerja dan bekerja pada masing-masing kelompok; setelah selesai, dua siswa dari masingmasing kelompok akan meninggalkan kelompoknya dan masing-masing bertamu ke kelompok yang lain; Dua siswa yang tinggal dalam kelompok bertugas membagikan hasil kerja dan informasi mereka ke tamu mereka dan tamu meminta izin dan kembali ke kelompok mereka sendiri dan melaporkan temuan mereka dari kelompok lain [9]

\section{HASIL DAN PEMBAHASAN}

Populasi penelitian adalah siswa kelas XI IPA SMA Plus Negeri 7 Kota Bengkulu dan sampel dipilih 2 kelas yaitu XI IPA 2 dan XI IPA 3. Pada penelitian ini kelas eksperimen1 (XI IPA 2) dan model pembelajaran two stay two stray pada kelas eksperimen 2 (XI IPA 3),

Dari hasil penelitian yang telah dilakukan didapatkanlah hasil belajar sebagai berikut,

Tabel 1. Data nilai rata-rata kelas eksperimen 1

\begin{tabular}{ll}
\hline \multicolumn{1}{c}{$\begin{array}{c}\text { Variabel } \\
\text { Model pembelajaran }\end{array}$} & \multicolumn{1}{c}{ Learning cycle } \\
\hline Jumlah siswa & 36 orang \\
Hasil pretest pertemuan 1 & 24,4722 \\
Hasil pretest pertemuan 2 & 37,361 \\
Hasil postest pertemuan 1 & 76,583 \\
Hasil postest pertemuan 2 & 80,806 \\
Rata-rata pretest & 30,917 \\
Rata-rata postest & 78,694 \\
Selisih nilai rata-rata & 47,778 \\
\hline
\end{tabular}

Untuk data hasil belajar siswa kelas eksperimen 2 dapat dilihat pada Tabel 2 .

Tabel 2. Data nilai rata rata kelas eksperimen 2

\begin{tabular}{|c|c|}
\hline $\begin{array}{c}\text { Variabel } \\
\text { Model pembelajaran }\end{array}$ & $\begin{array}{c}\text { two stay two } \\
\text { stray }\end{array}$ \\
\hline Jumlah siswa & 36 orang \\
\hline Hasil pretest pertemuan 1 & 30,806 \\
\hline Hasil pretest pertemuan 2 & 25,611 \\
\hline Hasil postest pertemuan 1 & 81,000 \\
\hline Hasil postest pertemuan 2 & 85,167 \\
\hline Rata-rata pretest & 28,208 \\
\hline Rata-rata postest & 83,083 \\
\hline Selisih nilai rata-rata & 54,875 \\
\hline
\end{tabular}

Pada Tabel 1 dan Tabel 2 tersebut dapat dilihat bahwa nilai rata-rata pretest dari dua kelas eksperimen tersebut masih dibawah nilai ketuntasan dimana nilai ketuntasan yang ditentukan sekolah untuk mata pelajaran kimia adalah 74. Pada kedua tabel tersebut 
juga dapat dilihat bahwa nilai rata-rata posttest dari dua kelas eksperimen tersebut mengalami peningkatan yang signifikan dari nilai rata-rata pretest. Terlihat pada kedua tabel, bahwa semua siswa kelas eksperimen 1 dan kelas eksperimen 2 memperoleh nilai diatas nilai ketuntasan. Hal ini berarti bahwa siswa telah memiliki pengetahuan untuk materi pelajaran titrasi asam basa dengan dapat menjawab semua soal uraian pada postest yang diberikan. Perbedaan nilai postest yang signifikan ini menunjukkan bahwa tingkat pemahaman siswa terhadap materi pelajaran juga berbeda. Tingginya nilai postest kelas eksperimen 2 dengan model pembelajaran two stay two stray mengindikasikan tingkat pemahaman siswa kelas eksperimen 1 berbeda dari tingkat pemahaman siswa kelas eksperimen 2 dengan model pembelajaran Learning cycle.

Hasil uji hipotesis dengan Uji t diperoleh hasil $t_{\text {hitung }}(2,60)>t_{\text {tabel }}(2,380)$. Hal ini menunjukkan bahwa ada perbedaan yang signifikan antara hasil belajar yang diperoleh dengan menggunakan kedua metode. Dari hasil penelitian dapat disimpulkan bahwa diantara kedua model pembelajaran tersebut, model pembelajaran two stay two stray lebih efektif dalam meningkatkan hasil belajar kimia siswa di sekolah dibandingkan model Learning Cycle. Hal ini sesuai dengan hasil penelitian sebelumnya, yang mendapatkan bahwa model pembelajaran two stay two stray dapat meningkatkan hasil dan minat belajar siswa dengan cara yang efektif [10. 11].

\section{KESIMPULAN}

Adapun dari hasil penelitian yang telah dilakukan dan telah dijelaskan, peneliti dapat mengambil kesimpulan berdasarkan tujuan adalah, hasil belajar kimia siswa dengan menggunakan model pembelajaran learning cycle dan model pembelajaran two stay two stray sama-sama meningkat. Dari hasil penelitian yang telah dilakukan terdapat perbedaan yang signifikan antara kedua model pembelajaran tersebut yang dibuktikan oleh uji hipotesis didapatkan nilai untuk t hitung sebesar 2,60 dan untuk $t_{\text {tabel }}$ didapatkan nilai sebesar 2,380. Hasilnya ternyata $t_{\text {hitung }}>t_{\text {tabel }}$. Artinya pernyataan hipotesis $\mathrm{Ha}$ diterima dan $\mathrm{H}_{0}$ ditolak

\section{SARAN}

Untuk penelitian lanjutan disarankan, lebih menekankan kedisiplinan terhadap waktu. Pembelajaran dengan membentuk kelompok memang memakan waktu yg cukup banyak namun jika mengaturnya dengan baik, maka akan jadi model pembelajaran yang efektif. ditambahkan media-media yang menarik agar siswa lebih tertarik untuk mengikuti kegiatan pembelajaran

\section{DAFTAR PUSTAKA}

[1] Herawati. 2015. Penerapan Model Pembelajaran Two Stay Two Stray Untuk Meningkatkan Prestasi Belajar Siswa Pada Materi Keliling dan Luas Lingkaran di Kelas VI SD Negeri 53 Banda Aceh. Banda Aceh. http://jurnal.unsyiah.ac.id.

[2] Rahayuningsih, Rina. 2012. Penerapan Siklus Belajar 5e (Learning Cycle 5e) Disertai Peta Kon-sep Untuk Meningkatkan Kualitas Proses dan Ha-sil Belajar Kimia Pada Materi Kelarutan dan Hasil Kali Kelarutan Kelas Xi IPA SMA Negeri 1 Kartasura Tahun Pelajaran 2011/2012. http:// eprints. uns.ac.id.

[3] Latif, Abdul. 2007. Pendidikan Berbasis Nilai Kemasyarakatan. Bandung : Refika Aditama (ISBN. 979-1073-92-9)

[4] Prayitno. 2009. Dasar Teori dan Praksis Pendidikan. Jakarta: GRASINDO (ISBN. 9789790259638).

[5] Ismawati. N. 2011. Penerapan Model Pembelajaran Kooperatif Dengan Pendekatan Struktural Two Stay Two Stray Untuk Meningkatkan Hasil Belajar Siswa Kelas X SMA. http://journal.unnes.ac.id.

[6] Sari, Ellies Septiana. 2014. Penerapan Model Pembelajaran Learning Cycle 5E Untuk Meningkatkan Aktivitas dan Prestasi Belajar Fisika Siswa Kelas X-Keperawatan SMK Kesehatan BIM Probolinggo. Malang. PMIPA Universitas NegeriMalang.http://www.karya-ilmiah.um.ac.id.

[7] Sumarni, Woro. 2010. Penerapan Learning Cycle Sebagai Upaya Meningkatkan Keterampilan Generik Sains Inferensia Logika Mahasiswa Melalui perkuliahan praktikum kimia dasar. Semarang. FMIPA Universitas Semarang. http://journal. unnes.ac.id

[8] Kulsum. U. 2011. Penerapan Model Learning Cycle Pada Sub Pokok Bahasan Kalor Untuk Meningkatkan Keaktifan dan Hasil Belajar Siswa Kelas VII SMP. http://journal.unnes.ac.id.

[9] Sudarmadi, Yedut. 2012. Efektifitas Pembelajaran Matematika Dengan Model Two Stay Two Stray dan Learning Together Ditinjau Dari Aktifitas Belajar Siswa Tahun Pelajaran 2011/ 2012. http:// perpustakaan.uns.ac.id.

[10] Hadiningrum, Nikke. 2012. Upaya Peningkatan Hasil Belajar Siswa Melalui Penerapan Model Pembelajaran Kooperatif Tipe Two Stay Two Stray Pada Kompetensi Dasar Mengelola Buku Besar Perusahaan Dagang. Surabaya. FE Universitas Surabaya. http;//ejournal.unesa.ac.id.

[11] Sulisworo, Dwi. 2014. The Effect of Cooperative Learning, Motivation and Information Technology Literacy to Achievement. Yogyakarta. International Journal of Learning \& Development. http;//www.macrothink.org 
Penulisan Sitasi Artikel ini ialah :

Gayatri, E.R.P, Bahar, A, Handayani, D, 2017, Perbandingan Penerapan Model Pembelajaran Learning Cycle (5E) dan Two Stay Two Stray, Alotrop, 1(1):7174 